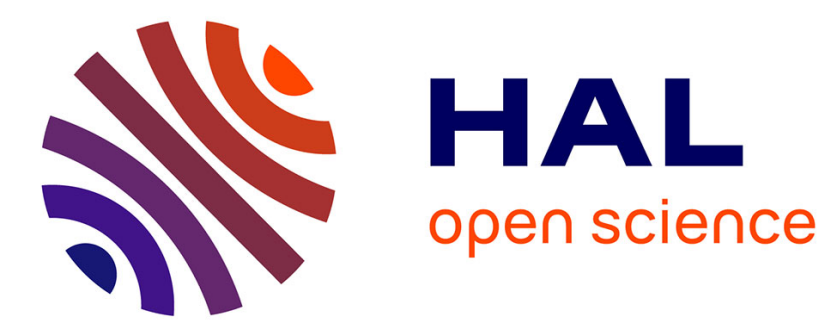

\title{
Unsolved issues related to human mitochondrial diseases.
}

Anne Lombès, Karine Auré, Christine Bellanné-Chantelot, Mylène Gilleron, Claude Jardel

\section{- To cite this version:}

Anne Lombès, Karine Auré, Christine Bellanné-Chantelot, Mylène Gilleron, Claude Jardel. Unsolved issues related to human mitochondrial diseases.. Biochimie, 2014, 100, pp.171-6. 10.1016/j.biochi.2013.08.012 . inserm-00877429

\section{HAL Id: inserm-00877429 https://www.hal.inserm.fr/inserm-00877429}

Submitted on 28 Oct 2013

HAL is a multi-disciplinary open access archive for the deposit and dissemination of scientific research documents, whether they are published or not. The documents may come from teaching and research institutions in France or abroad, or from public or private research centers.
L'archive ouverte pluridisciplinaire HAL, est destinée au dépôt et à la diffusion de documents scientifiques de niveau recherche, publiés ou non, émanant des établissements d'enseignement et de recherche français ou étrangers, des laboratoires publics ou privés. 


\section{Unsolved issues related to human mitochondrial diseases}

Anne Lombès ${ }^{1,2,3^{*}}$, Karine Auré1,4,5 , Christine Bellanné-Chantelot ${ }^{3}$, Mylène Gilleron ${ }^{1,3}$, Claude Jardel $^{1,3}$

${ }^{1}$ Inserm Institut Cochin U1016 ; CNRS UMR 8104, 24 rue du Fb St Jacques Paris F-75014 France

${ }^{2}$ Université Paris-Descartes-Paris5, Paris, F-75014 France

${ }^{3}$ AP-HP, Service de Biochimie Métabolique et Centre de Génétique moléculaire et chromosomique, GHU Pitié-Salpêtrière, Paris, F-75651 France

${ }^{4}$ AP-HP, Hôpital Ambroise Paré, Service d'explorations fonctionnelles, Boulogne-Billancourt, F92100 France;

${ }^{5}$ Université Versailles-Saint-Quentin en Yvelines, F-78180 France;

Authors e-mail addresses: anne.lombes@inserm.fr, karine.aure@apr.aphp.fr, Christine.bellannechantelot@psl.aphp.fr, mylene.gilleron@psl.aphp.fr, claude.jardel@psl.aphp.fr

*To whom correspondence should be sent at Inserm U1016, Institut Cochin, Faculté de Médecine 24 rue du Fb St Jacques 75014 Paris France telephone (33)1 53732751 e-mail:

anne.lombes@inserm.fr 


\begin{abstract}
Human mitochondrial diseases, defined as the diseases due to a mitochondrial oxidative phosphorylation defect, represent a large group of very diverse diseases with respect to phenotype and genetic causes. They present with many unsolved issues, the comprehensive analysis of which is beyond the scope of this review. We here essentially focus on the mechanisms underlying the diversity of targeted tissues, which is an important component of the large panel of these diseases phenotypic expression. The reproducibility of genotype/phenotype expression, the presence of modifying factors, and the potential causes for the restricted pattern of tissular expression are reviewed.

Special emphasis is made on heteroplasmy, a specific feature of mitochondrial diseases, defined as the coexistence within the cell of mutant and wild type mitochondrial DNA molecules. Its existence permits unequal segregation during mitoses of the mitochondrial DNA populations and consequently heterogeneous tissue distribution of the mutation load. The observed tissue distributions of recurrent human mitochondrial DNA deleterious mutations are diverse but reproducible for a given mutation demonstrating that the segregation is not a random process. Its extent and mechanisms remain essentially unknown despite recent advances obtained in animal models.
\end{abstract}

\title{
Keywords
}

Mitochondrial DNA, heteroplasmy, oxidative phosphorylation, human diseases, tissue specificity Abbreviations: OXPHOS: oxidative phosphorylation pathway; mtDNA: mitochondrial DNA; 


\section{Introduction}

The definition of mitochondrial disease has long been debated and two main definitions still coexist: one restricts these diseases to those due to an alteration of the mitochondrial oxidative phosphorylation pathway (OXPHOS) [1] while the second one encompasses all the diseases due to the alteration of a mitochondrial component [2]. The second definition has at least two disadvantages with respect to the medical point of view. It puts together diseases with pathophysiological mechanisms that totally differ from those expected from an OXPHOS defect. Striking examples are the acute intoxication by ammonia due to OTC or CPS mutations or the defective cortisol and corticosterone biosynthesis due to CYP11B1 mutations. Conversely it excludes diseases due to the alteration of a non-mitochondrial component that induces an OXPHOS defect. A well known example of that situation is the MNGIE (MyoNeuroGastroIntestinal Encephalopathy) syndrome due to mutations of TYMP encoding a cytosolic thymidine phosphorylase whose defect induces depletion of the mitochondrial DNA (mtDNA). In this review addressing the medical relevance of unsolved issues related to mitochondrial diseases, we define these diseases as those due to an OXPHOS defect.

Within that definition, mitochondrial diseases present with many unsolved issues such as the relative role of the diverse facets of the bioenergetic defect, the amplitude and potential compensation of the induced modification of reactive oxygen species metabolism and/or apoptosis balance, and the interplay between altered mitochondrial signaling and cellular compensatory responses. These aspects are most often addressed in cellular models, which may lack relevance as cultured cells essentially rely on glycolysis for the energy production. Because of their direct impact on diagnosis, prognosis and/or therapeutic approaches of mitochondrial diseases this review will focus on the mechanisms underlying the extreme phenotypic diversity of mitochondrial diseases, and especially heteroplasmy, i.e. the coexistence within the cell of mutant and wild type mtDNA molecules, which is frequent with deleterious mtDNA mutations. 


\section{The extreme phenotypic diversity of mitochondrial diseases is related to the diversity of the deleterious consequences of the causal genetic alterations.}

Signs/symptoms encountered in mitochondrial diseases are extremely diverse (Table 1). They may affect any organ. Furthermore within an organ or tissue they may involve different target cells (for example proximal tubular cells or glomerules in kidney) and/or imply different mechanisms (for example permanent muscle weakness with TK2 mutations vs isolated intolerance to exercise with $M T-C Y B$ mutations or rapid progression to cirrhosis with DGUOK or BCS1L mutations vs recurrent accesses of liver insufficiency with full recovery with UQCRB mutations).

That extreme phenotypic diversity appears essentially related to the diversity of the causes. Indeed specific mutations most often reproducibly give identical or similar phenotype. This is commonly observed with mutations of nuclear DNA genes such as TK2, TYMP or DGUOK [3]. It is also encountered with mtDNA mutations. The three most recurrent mtDNA alterations (large size unique deletion, m.3243A >G MELAS and m.8344A>G MERRF mutation) have now been found in hundreds of patients. Their phenotypes share several common points but they also have unique features that often permit their recognition and, most importantly, indicate that they induce, at least partly, different mechanisms. The presence of lipomas for example is only observed with the m.8344A $>$ G mutations and not with any other mtDNA-encoded tRNA genes. Although there always are overlapping or border cases, these are the minority and are over-represented in the literature.

Restricted tissue expression of the altered gene could explain part of the phenotypic diversity (see below). It cannot explain the diverse deleterious consequences within a same tissue. Our knowledge of the link between mutation and symptoms is clearly insufficient. Dissecting out that link requires on the one hand complete understanding of the symptoms, which may be very difficult when dealing with very complex organs such as brain, and comprehensive analysis of the mutation molecular and cellular consequences, which obviously can only be addressed in surrogate models, either cells derived from patients or genetically-modified animals. 


\section{The influence of modifying factors could be demonstrated in few instances}

Modifying factors have been proposed to explain part of the phenotypic diversity observed with mitochondrial diseases. They cannot be demonstrated without sufficient recurrence of identical mutations as different mutations of the same gene may have significantly different impact. Such recurrence is rare in mitochondrial diseases because of the large genetic heterogeneity of these diseases.

The presence of modifying factors could however be demonstrated in diseases due to mutations of the POLG or TK2 nuclear genes and of the mtDNA-encoded ND1, ND4 and ND6 genes causing Leber Hereditary Optic Neuropathy (LHON). They were proposed to underlie the absence of symptoms despite the presence of the mutations in LHON [4] or to significantly modify the presentation in the case of POLG or TK2 [5, 6].

The nature of these modifying factors would be essential to unravel as it would indicate the mechanisms allowing efficient modulation of the clinical consequences of the OXPHOS defect. The main candidate genetic modifiers have been the mtDNA haplogroup and nuclear genes encoding mtDNA replication factors [6, 7]. Despite longstanding and intensive efforts in the case of LHON the modifying nuclear genes have however remained elusive [8-10]. The influence of the mtDNA haplogroup has been repeatedly proposed but has remained a likely hypothesis in the absence of reliable functional assay [11, 12]. Only few attempts have been made to address the possible modulation of genetic OXPHOS defects. Among these it is interesting to note that several methods aiming at the increase of mtDNA expression through overexpression of translation factors [13] or induction of mitochondrial biogenesis $[14,15]$ has shown promising efficacy.

\section{Restricted tissue expression of an OXPHOS defect may have numerous potential causes}

The restricted tissue expression of mitochondrial diseases can be ascribed to, at least, two different mechanisms. The first one is the restricted tissue expression of nuclear genes either the 
gene whose defect causes the disease and/or the genes involved in the cellular responses to the OXPHOS defect; the second mechanism is specific for heteroplasmic mtDNA mutation whose proportion may be heterogeneous between tissues. That latter phenomenon will be discussed in a specific chapter as it is both highly relevant to diseases and raises numerous unsolved issues.

Several genes responsible for a restricted pattern of symptoms are ubiquitously expressed. This is the case for example of $T K 2$ whose mutations induce an essentially isolated severe myopathy or for GFM1 associated with hepatopathy. The steady-state expression of the gene in the target tissue does not seem to be a predictive factor of the tissue-specific expression of the disease. Indeed it was low in muscle for TK2 [16] but high in liver for GFM1 [17].

Restricted expression of gene(s) involved in the pathway targeted by the causal defect has also been proposed to play a role in the disease tissue-specific expression [17]. In that case it is the lack of appropriate compensation by these genes that would explain tissue sensitivity to the causal defect. That hypothesis has been supported by the observation of phenotypic improvement upon overexpression of the genes [13]. It is however lacking demonstration in human patients.

An alternative hypothesis for the restricted sensitivity of certain tissues to generalized defects is the presence of specific energy-demanding mechanisms within these tissues. That hypothesis has been proposed for the urinary loss of substrates normally actively reabsorbed in proximal tubules or the severe intolerance to exercise observed in several mitochondrial diseases. It could underlie the prominent neuronal dysfunction as ionic transport is together a highly energy-consuming process and the basis of neuronal life. However these diverse signs/symptoms do not directly correlate with the severity of the energy deprivation; in particular they can lack in apparently severe generalized OXPHOS defect. Our lack of knowledge of the expression of the diverse mitochondrial diseases in the different tissues greatly hampers further understanding of that issue.

Quantitative expression of OXPHOS itself has been proposed to underlie the predominant neuromuscular expression of mitochondrial diseases, the understatement being that tissues with high OXPHOS levels must strictly depend on their aerobic metabolism. This cannot be a 
straightforward simple explanation as, for example, heart is extremely rich in OXPHOS complexes that represent up to $20 \%$ of its mitochondrial inner membrane proteins. Nevertheless several generalized OXPHOS defects, due for example to mutations in mtDNA-encoded complex I

subunits, present with severe brain disease but no heart symptoms. The role of the different amount of respiratory complexes between tissues in the impact of an OXPHOS defect thus remains to be deciphered.

In addition to the global amount of OXPHOS, the relative ratio between complexes can significantly vary between tissues. In human clinical practice, muscle, liver and cultured skin fibroblasts are the most frequently assayed tissues. Even within that limited number of tissues, the levels of maximal velocity of each complex but also to the relative ratio between complexes appear clearly different (Figure 1A). Animal models allow addressing these differences. Indeed, similarly to human tissues, mouse muscle presents with higher complex IV, similar complex I and lower complex II than mouse liver. The overall mitochondrial activities are however much higher in mice than in humans (Figure 1B). Analysis with western blot on post nuclear supernatants from different mouse tissues confirms that different tissues present with striking differences in the ratio between complexes (Figure 1C). Whether these different amounts and relative ratios have significant impact on the response to OXPHOS defect remains to be determined.

\section{Heteroplasmy has relevant consequences for human diseases}

Heteroplasmy is specific for mtDNA mutations. It has several highly relevant consequences for human diseases.

\subsection{Most deleterious mtDNA mutations only induce defects when present in a very high proportion}

Enzymatic defects and their ensuing symptoms only occur when the mutation reaches a threshold proportion, which depends both on the organ and nature of the mutation but is often very high (above 80\%). Lowering even partially the mutation load could therefore significantly improve 
the phenotype. Several attempts have been done towards that direction either targeting the replication of the mutant mitochondrial DNA in cellular or animal models $[18,19]$ or selecting for cells with lower mutation load in cellular models and in patients [20-22]. Although establishing the proof of principle these attempts have yet too show their efficacy on a broader field.

\subsection{Mitotic segregation allows highly heterogeneous tissue distribution of heteroplasmic}

\section{mutations}

\subsubsection{Clinical observations}

The coexistence of the two mtDNA populations leaves open the possibility of their unequal segregation during mitoses. Blood carrying the deleterious "MELAS" mutation (m.3243A>G) has been shown to decrease its mutation load with age [23]. Conversely muscle seems to progressively increase with age its mutation load in patients with inherited mtDNA deletion [24] or point mutation [25]. Normal ageing is accompanied by the progressive accumulation of low proportions of mtDNA deletions and point mutations in post-mitotic tissues [26].

Clonal expansion, equivalent to extreme segregation, of one of these mtDNA alterations has been shown to be at the basis of the observed OXPHOS defect in muscle [27, 28], colon [29] and brain [30]. These studies confirmed that the threshold mutation proportion, inducing OXPHOS defect, was very high, often close to homoplasmy. Even a modest modulation of segregation could therefore significantly modify the resulting phenotype [31].

Clinical practice shows that unequal segregation with subsequent heterogeneous mutation load between tissues is frequent [32, 33]. The diverse mtDNA-encoded deleterious point mutations fall into two categories with respect to their tissue distribution with most mutations presenting with a heterogeneous tissue distribution and some with a homogeneous one (Figure 2A and 2B). Clinical practice also shows that the process is not random as recurrent mutations had highly reproducible pattern for a given mutation. This is exemplified with the most recurrent mtDNA-encoded tRNA mutations: "MELAS” (m.3243A>G) and "MERRF" (m.8244A>G) mutations that we have to-date identified in dozens of patients (Figure 2C). In our experience, these two mutations presented with 
completely different segregation behavior. The MERRF mutation did not appear actively segregated as its proportion was homogeneous in blood, buccal cells and urinary sediment in 27 independent patients (mutation load differences between blood and buccal cells or urinary sediment close to zero and $\mathrm{p}=0.251$ when comparing the two differences). This contrasted strikingly with the MELAS mutation whose mutation load significantly decreased from urinary sediment to buccal cells and blood ( $<<0.001$ for each pair-wise comparison). Even if there are rare outlier points, active segregation, specific for some mutations, is thus undergoing but we do not understand the mechanisms underlying that observation.

\subsubsection{Lessons from animal models}

Rare heteroplasmic animal models have been obtained and allow addressing the tissular segregation. The most well studied one carried two different normal mtDNA obtained by cytoplast transfer into one cell-embryo [34]. These two different normal mtDNA were found to be actively segregated for during the animal lifespan, in a non-random fashion as one genotype was favored in kidney and liver while the other one was favored in blood and spleen [35]. Using linkage analysis and crosses with distantly related mouse species, Battersby et al found three potential loci controlling the tissular segregation [36] and, more recently, identified GIMAP3 as a gene controlling active mtDNA segregation in blood [37]. How this gene can influence the fate of a normal mtDNA still remains an open question.

\subsubsection{Clinical consequences of heterogeneous tissue distribution}

One consequence of the pattern of tissue repartition is that it has to be taken into account by the diagnosis protocols. In contrast to the investigations of nuclear genes, blood cannot be considered as representative for the whole individual. In theory diagnostic investigations should always be performed on samples from a tissue affected by the disease. Surrogate tissues are however often used instead of the target tissue, for example in patients with essentially brain symptoms. The potential risk is then to get false negative results, in particular in the presence of extreme segregation (Figure 2A, mutation m.10014G>A). The issue of tissue distribution is also highly 
relevant to prognosis, which depends on the mutation load in the different tissues, particularly in brain.

\subsection{Segregation of mutations through generations}

Segregation also occurs before birth and has been involved in the rapid return to homoplasmy of heteroplasmic mtDNA molecules through what was called the genetic bottleneck [38]. It can theoretically take place at any step from the differentiation of primordial germinal cells, through their maturation into mature ovule, fecundation and embryogenesis.

\subsubsection{Observations in humans}

The segregation pattern seems different during oogenesis and during embryogenesis [39]. There again the segregation pattern depended on the nature of the mutation as mutations such as the m.8993T $>$ G in MT-ATP6 gene rapidly shifted towards homoplasmy [40] while the MELAS mutation seemed to follow a more random pattern [39].

5.3.2 Lessons from animal models

Animal models have been used to address the existence and mechanisms of the genetic bottleneck. Transmission of heteroplasmic normal genotypes has shown that the bottleneck was due to low mtDNA copy number in oogonia but also to preferential amplification of mtDNA subpopulations during folliculogenesis [41, 42].

Transmission of the deleterious mutations created by an exonuclease deficient mtDNA polymerase gamma has shown strong purifying selection against the most deleterious mutations [43]. Intriguingly mice harboring low proportions of a deleterious MT-ND6 frame-shift mutation were shown to transmit less and less of the mutation in their successive progeny, which would implicate some on-going selection at the ovarian level [44].

5.3.3 Clinical consequences of segregation through generations

With regards to clinical practice, segregation through generations has direct relevance to genetic counseling and the feasibility of prenatal diagnosis. There are still numerous questions regarding the extent of post-natal segregation that may occur during a lifespan. Several children with low 
proportions of a deleterious mtDNA mutation have now been born after prenatal diagnosis [39]. Their long term follow up will be essential to carefully record.

\section{Conclusion}

The extreme phenotypic diversity of mitochondrial diseases represents a great challenge for the medical community. It obviously renders difficult the diagnosis of the diseases but, more importantly, it shows that the involved deleterious mechanisms may be very diverse. The nature of the genetic defect is clearly very important but the multiple aspects of the target tissues are most probably as important, including the cell dependence on specific energy-requiring pathways and its capacity to develop adequate compensatory responses.

Heteroplasmy is only one aspect of that diversity. Understanding the mechanisms of segregation of heteroplasmic mtDNA mutations would be essential for the care of patients. At the diagnosis level it would allow choosing the samples avoiding false negative results; it would provide an insight on the potential evolution of the mutation load during the patients' lifespan; it might open possibilities for heteroplasmy modulation.

\section{Acknowledgements}

The authors wish to thank the patients and their family for their trust and comprehension for our insufficient knowledge.

This work was supported by grants from the Association Française contre les Myopathies (AFM), from the Association contre les Maladies Mitochondriales (AMMi), and from the Fondation pour la Recherche Médicale (FRM) to AL.

\section{References}

[1] DiMauro S., Mitochondrial diseases, Biochim. Biophys. Acta 1658 (2004) 80-88. 
[2] Koopman W.J., Willems P.H., Smeitink J.A., Monogenic mitochondrial disorders, N. Engl. J. Med. 366 (2012) 1132-1141.

[3] Spinazzola A., Invernizzi F., Carrara F., Lamantea E., Donati A., Dirocco M., Giordano I., Meznaric-Petrusa M., Baruffini E., Ferrero I., Zeviani M., Clinical and molecular features of mitochondrial DNA depletion syndromes, J. Inherit. Metab. Dis. 32 (2009) 143-158.

[4] Riordan-Eva P., Sanders M.D., Govan G.G., Sweeney M.G., DaCosta J., Harding A.E., The clinical features of Leber's hereditary optic neuropathy defined by the presence of a pathogenic mitochondrial DNA mutation, Brain 118(2) (1995) 319-337.

[5] Béhin A., Jardel C., Claeys K.G., Fagart J., Louha M., Romero N.B., Laforêt P., Eymard B., Lombès A., Adult cases of mitochondrial DNA depletion due to TK2 defect: an expanding spectrum, Neurology 78 (2012) 644-648.

[6] Neeve V.C., Samuels D.C., Bindoff L.A., van den Bosch B., Van Goethem G., Smeets H., Lombes A., Jardel C., Hirano M., Dimauro S., De Vries M., Smeitink J., Smits B.W., de Coo I.F., Saft C., Klopstock T., Keiling B.C., Czermin B., Abicht A., Lochmuller H., Hudson G., Gorman G.G., Turnbull D.M., Taylor R.W., Holinski-Feder E., Chinnery P.F., Horvath R., What is influencing the phenotype of the common homozygous polymerase-gamma mutation p.Ala467Thr?, Brain 135 (2012) 3614-3626.

[7] Hudson G., Carelli V., Spruijt L., Gerards M., Mowbray C., Achilli A., Pyle A., Elson J., Howell N., La Morgia C., Valentino M.L., Huoponen K., Savontaus M.L., Nikoskelainen E., Sadun A.A., Salomao S.R., Belfort R., Jr., Griffiths P., Man P.Y., de Coo R.F., Horvath R., Zeviani M., Smeets H.J., Torroni A., Chinnery P.F., Clinical expression of Leber hereditary optic neuropathy is affected by the mitochondrial DNA-haplogroup background, Am. J. Hum. Genet. 81 (2007) 228233.

[8] Hudson G., Yu-Wai-Man P., Griffiths P.G., Caporali L., Salomao S.S., Berezovsky A., Carelli V., Zeviani M., Chinnery P.F., Variation in OPA1 does not explain the incomplete penetrance of Leber hereditary optic neuropathy, Mol. Vis. 16 (2010) 2760-2764. 
[9] Hudson G., Yu-Wai-Man P., Zeviani M., Chinnery P.F., Genetic variation in the methylenetetrahydrofolate reductase gene, MTHFR, does not alter the risk of visual failure in Leber's hereditary optic neuropathy, Mol. Vis. 15 (2009) 870-875.

[10] Hudson G., Keers S., Yu Wai Man P., Griffiths P., Huoponen K., Savontaus M.L., Nikoskelainen E., Zeviani M., Carrara F., Horvath R., Karcagi V., Spruijt L., de Coo I.F., Smeets H.J., Chinnery P.F., Identification of an X-chromosomal locus and haplotype modulating the phenotype of a mitochondrial DNA disorder, Am. J. Hum. Genet. 77 (2005) 1086-1091.

[11] Moreno-Loshuertos R., Acin-Perez R., Fernandez-Silva P., Movilla N., Perez-Martos A., Rodriguez de Cordoba S., Gallardo M.E., Enriquez J.A., Differences in reactive oxygen species production explain the phenotypes associated with common mouse mitochondrial DNA variants, Nat. Genet. 38 (2006) 1261-1268.

[12] Battersby B.J., Shoubridge E.A., Reactive oxygen species and the segregation of mtDNA sequence variants, Nat. Genet. 39 (2007) 571-572; author reply 572.

[13] Sasarman F., Antonicka H., Shoubridge E.A., The A3243G tRNALeu(UUR) MELAS mutation causes amino acid misincorporation and a combined respiratory chain assembly defect partially suppressed by overexpression of EFTu and EFG2, Hum Mol Genet 17 (2008) 3697-3707. [14] Noe N., Dillon L., Lellek V., Diaz F., Hida A., Moraes C.T., Wenz T., Bezafibrate improves mitochondrial function in the CNS of a mouse model of mitochondrial encephalopathy, Mitochondrion (2013). doi: 10.1016

[15] Wenz T., Diaz F., Spiegelman B.M., Moraes C.T., Activation of the PPAR/PGC-1alpha pathway prevents a bioenergetic deficit and effectively improves a mitochondrial myopathy phenotype, Cell Metab. 8 (2008) 249-256.

[16] Saada A., Shaag A., Elpeleg O., mtDNA depletion myopathy: elucidation of the tissue specificity in the mitochondrial thymidine kinase (TK2) deficiency, Mol. Genet. Metab. 79 (2003) $1-5$. 
[17] Antonicka H., Sasarman F., Kennaway N.G., Shoubridge E.A., The molecular basis for tissue specificity of the oxidative phosphorylation deficiencies in patients with mutations in the mitochondrial translation factor EFG1, Hum. Mol. Genet. 15 (2006) 1835-1846.

[18] Taylor R.W., Wardell T.M., Smith P.M., Muratovska A., Murphy M.P., Turnbull D.M., Lightowlers R.N., An antigenomic strategy for treating heteroplasmic mtDNA disorders, Adv. Drug Deliv. Rev. 49 (2001) 121-125.

[19] Bayona-Bafaluy M.P., Blits B., Battersby B.J., Shoubridge E.A., Moraes C.T., Rapid directional shift of mitochondrial DNA heteroplasmy in animal tissues by a mitochondrially targeted restriction endonuclease, Proc. Natl Acad. Sci. U S A 102 (2005) 14392-14397.

[20] Manfredi G., Gupta N., Vazquez-Memije M.E., Sadlock J.E., Spinazzola A., De Vivo D.C., Schon E.A., Oligomycin induces a decrease in the cellular content of a pathogenic mutation in the human mitochondrial ATPase 6 gene, J. Biol. Chem. 274 (1999) 9386-9391.

[21] Clark K.M., Bindoff L.A., Lightowlers R.N., Andrews R.M., Griffiths P.G., Johnson M.A., Brierley E.J., Turnbull D.M., Reversal of a mitochondrial DNA defect in human skeletal muscle, Nat. Genet. 16 (1997) 222-224.

[22] Murphy J.L., Blakely E.L., Schaefer A.M., He L., Wyrick P., Haller R.G., Taylor R.W., Turnbull D.M., Taivassalo T., Resistance training in patients with single, large-scale deletions of mitochondrial DNA, Brain 131 (2008) 2832-2840.

[23] Rahman S., Poulton J., Marchington D., Suomalainen A., Decrease of 3243 A-->G mtDNA mutation from blood in MELAS syndrome: a longitudinal study, Am. J. Hum. Genet. 68 (2001) 238-240.

[24] Larsson N.G., Holme E., Kristiansson B., Oldfors A., Tulinius M., Progressive increase of the mutated mitochondrial DNA fraction in Kearns-Sayre syndrome, Pediatr Res 28 (1990) 131-136. [25] Weber K., Wilson J.N., Taylor L., Brierley E., Johnson M.A., Turnbull D.M., Bindoff L.A., A new mtDNA mutation showing accumulation with time and restriction to skeletal muscle, Am. J. Hum. Genet. 60 (1997) 373-380. 
[26] Cortopassi G.A., Shibata D., Soong N.W., Arnheim N., A pattern of accumulation of a somatic deletion of mitochondrial DNA in aging human tissues, Proc. Natl Acad. Sci. U S A 89 (1992) 7370-7374.

[27] Bua E., Johnson J., Herbst A., Delong B., McKenzie D., Salamat S., Aiken J.M., Mitochondrial DNA-deletion mutations accumulate intracellularly to detrimental levels in aged human skeletal muscle fibers, Am. J. Hum. Genet. 79 (2006) 469-480.

[28] Fayet G., Jansson M., Sternberg D., Moslemi A.R., Blondy P., Lombès A., Fardeau M., Oldfors A., Ageing muscle: clonal expansions of mitochondrial DNA point mutations and deletions cause focal impairment of mitochondrial function, Neuromuscul. Disord. 12 (2002) 484-493.

[29] Greaves L.C., Preston S.L., Tadrous P.J., Taylor R.W., Barron M.J., Oukrif D., Leedham S.J., Deheragoda M., Sasieni P., Novelli M.R., Jankowski J.A., Turnbull D.M., Wright N.A., McDonald S.A., Mitochondrial DNA mutations are established in human colonic stem cells, and mutated clones expand by crypt fission, Proc. Natl Acad. Sci. U S A 103 (2006) 714-719.

[30] Bender A., Krishnan K.J., Morris C.M., Taylor G.A., Reeve A.K., Perry R.H., Jaros E., Hersheson J.S., Betts J., Klopstock T., Taylor R.W., Turnbull D.M., High levels of mitochondrial DNA deletions in substantia nigra neurons in aging and Parkinson disease, Nat. Genet. 38 (2006) 515-517.

[31] Chinnery P.F., Modulating heteroplasmy, Trends Genet. 18 (2002) 173-176.

[32] Shanske S., Moraes C.T., Lombès A., Miranda A.F., Bonilla E., Lewis P., Whelan M.A., Ellsworth C.A., DiMauro S., Widespread tissue distribution of mitochondrial DNA deletions in Kearns-Sayre syndrome, Neurology 40 (1990) 24-28.

[33] Shanske S., Pancrudo J., Kaufmann P., Engelstad K., Jhung S., Lu J., Naini A., DiMauro S., De Vivo D.C., Varying loads of the mitochondrial DNA A3243G mutation in different tissues: implications for diagnosis, Am. J. Med. Genet. A 130A (2004) 134-137. 
[34] Jenuth J.P., Peterson A.C., Fu K., Shoubridge E.A., Random genetic drift in the female germline explains the rapid segregation of mammalian mitochondrial DNA, Nat. Genet. 14 (1996) 146-151.

[35] Jenuth J.P., Peterson A.C., Shoubridge E.A., Tissue-specific selection for different mtDNA genotypes in heteroplasmic mice, Nat. Genet. 16 (1997) 93-95.

[36] Battersby B.J., Loredo-Osti J.C., Shoubridge E.A., Nuclear genetic control of mitochondrial DNA segregation, Nat. Genet. 33 (2003) 183-186.

[37] Jokinen R., Marttinen P., Sandell H.K., Manninen T., Teerenhovi H., Wai T., Teoli D., Loredo-Osti J.C., Shoubridge E.A., Battersby B.J., Gimap3 regulates tissue-specific mitochondrial DNA segregation, PLoS Genet. 6 (2010) e1001161.

[38] Olivo P.D., Van de Walle M.J., Laipis P.J., Hauswirth W.W., Nucleotide sequence evidence for rapid genotypic shifts in the bovine mtDNA D-loop, Nature 306 (1983) 400-402.

[39] Monnot S., Gigarel N., Samuels D.C., Burlet P., Hesters L., Frydman N., Frydman R., Kerbrat V., Funalot B., Martinovic J., Benachi A., Feingold J., Munnich A., Bonnefont J.P., Steffann J., Segregation of mtDNA throughout human embryofetal development: m.3243A $>$ G as a model system, Hum. Mutat. 32 (2011) 116-125.

[40] Blok R.B., Gook D.A., Thorburn D.R., Dahl H.H., Skewed segregation of the mtDNA nt 8993 (T-->G) mutation in human oocytes, Am. J. Hum. Genet. 60 (1997) 1495-1501.

[41] Wai T., Teoli D., Shoubridge E.A., The mitochondrial DNA genetic bottleneck results from replication of a subpopulation of genomes, Nat. Genet. 40 (2008) 1484-1488.

[42] Cree L.M., Samuels D.C., de Sousa Lopes S.C., Rajasimha H.K., Wonnapinij P., Mann J.R., Dahl H.H., Chinnery P.F., A reduction of mitochondrial DNA molecules during embryogenesis explains the rapid segregation of genotypes, Nat. Genet. 40 (2008) 249-254.

[43] Stewart J.B., Freyer C., Elson J.L., Larsson N.G., Purifying selection of mtDNA and its implications for understanding evolution and mitochondrial disease, Nat. Rev. Genet 9 (2008) 657662. 
[44] Fan W., Waymire K.G., Narula N., Li P., Rocher C., Coskun P.E., Vannan M.A., Narula J., Macgregor G.R., Wallace D.C., A mouse model of mitochondrial disease reveals germline selection against severe mtDNA mutations, Science 319 (2008) 958-962.

[45] Medja F., Allouche S., Frachon P., Jardel C., Malgat M., de Camaret B.M., Slama A., Lunardi J., Mazat J.P., Lombes A., Development and implementation of standardized respiratory chain spectrophotometric assays for clinical diagnosis, Mitochondrion 9 (2009) 331-339. 


\section{Legends to figures}

\section{Figure 1: Relative amount of respiratory complexes in different tissues from humans and}

mouse.

A) Enzymatic activities taken from the results obtained in three different diagnostic centers using spectrophotometric analyses of patients who were deemed to be free of mitochondrial diseases [45]; B) Data from mouse tissues assayed with the same protocols as human samples. For liver, muscle or striatum, activities were measured on post-nuclear supernatants of tissue homogenates, which do not permit reliable measurement of ATP synthase activity (complex V). For fibroblasts activities were measured on whole cells homogenates where the measurement of complex I is unreliable; I= rotenone sensitive NADH ubiquinone oxidoreductase, II=succinate ubiquinone oxidoreductase, III=antimycin sensitive ubiquinol cytochrome c oxidoreductase, IV=cytochrome c oxidase, CS=citrate synthase;

C) Western blot analysis of post-nuclear supernatants of homogenates from mouse muscle (quadriceps), liver and brain using Mitoprofile antibodies containing a cocktail of monoclonal antibodies against subunit alpha of complex V (CV, MW=53 kDa), core 2 subunit of complex III (CIII, MW=47 kDa), SDHB subunit of complex II (CII, MW=30 kDa), MT6CO2 subunit of complex IV (CIV, MW=24 kDa) and NDUFB8 subunit of complex I (CI, MW=20 kDa). Loaded proteins were 20 and $10 \mu \mathrm{g}$ for each tissue.

Figure 2: Diverse patterns of the heteroplasmy tissue distribution of point mutations affecting mtDNA-encoded tRNA genes

A) Most point mutations of the mtDNA-encoded tRNA genes present with a heterogeneous tissue distribution with muscle $(\mathrm{M})$ having higher proportion than blood $(\mathrm{Bl})$, buccal cells $(\mathrm{Bu})$ or hair $(\mathrm{H})$. Cells from the urinary sediment (U) often have relatively high mutation load (see m.3243A $>G$ “MELAS” mutation). Rare patients present with extreme mutation segregation as shown with mutation m.10014G>A of glytRNA, which was almost homoplasmic in muscle but absent in all other tissues. 
B) In contrast some mutations of the mtDNA-encoded tRNA genes present with a homogeneous mutation load in every available tissue Blood (Bl), Urinary sediment (U), buccal cells (Bu), Hair (H), Muscle (M) or kidney (K).

C) Recurrent mutations allow demonstrating the reproducibility of the pattern of tissue distribution for a given mutation.

Boxplot of mutation load difference calculated by subtracting the mutation load in blood from that of buccal cells (Buccal cells-Blood, Bu-Bl) or from that of urinary sediment (Urinary sedimentBlood, Ur-Bl) in 123 patients with the m.3243A>G mutation ("MELAS”) and in 27 patients with the m.8344A>G mutation ("MERRF"). 


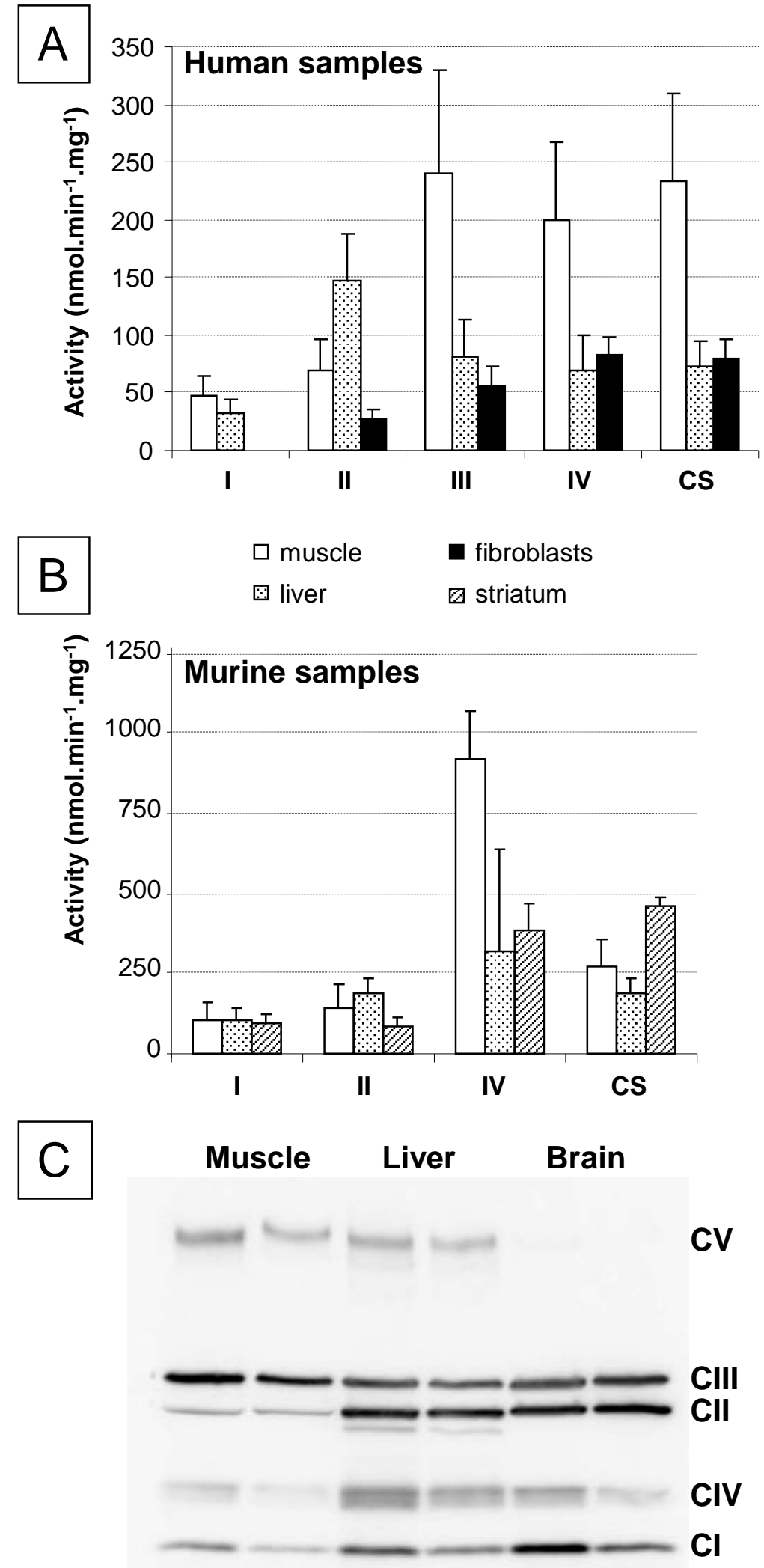

Figure 1 


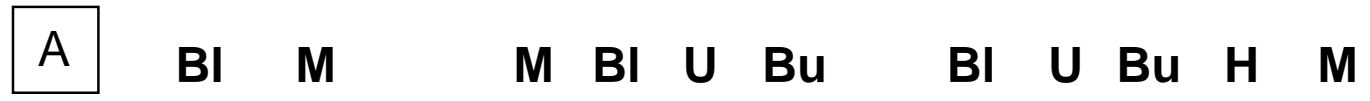

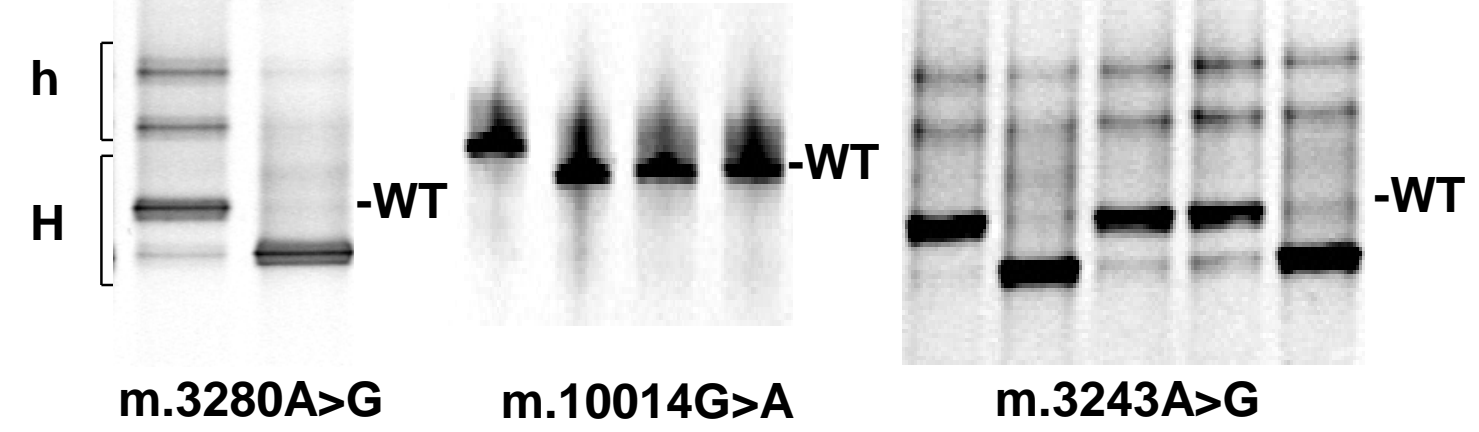

$B \quad B I \quad B \quad H \quad M \quad K$

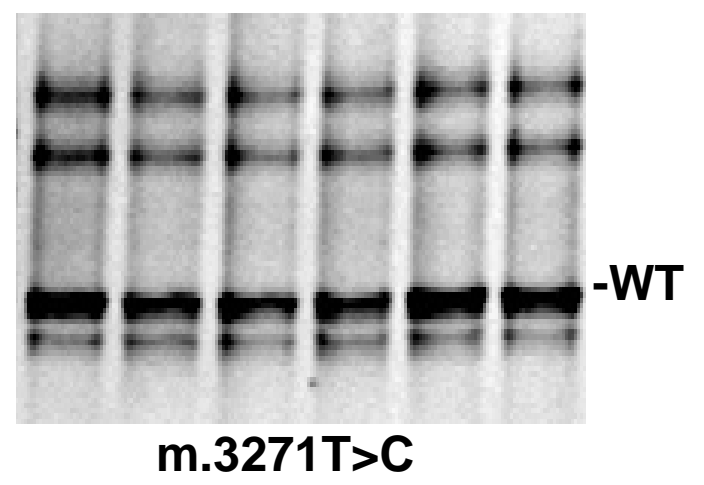

$\begin{array}{llll}\text { H } & \text { Bu } & \text { BI }\end{array}$

m.3271T >C

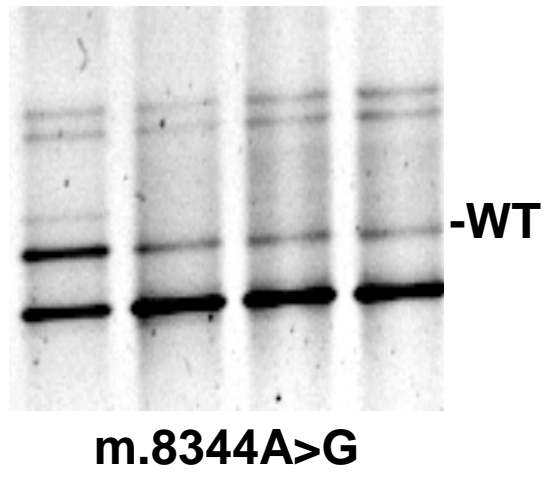

C

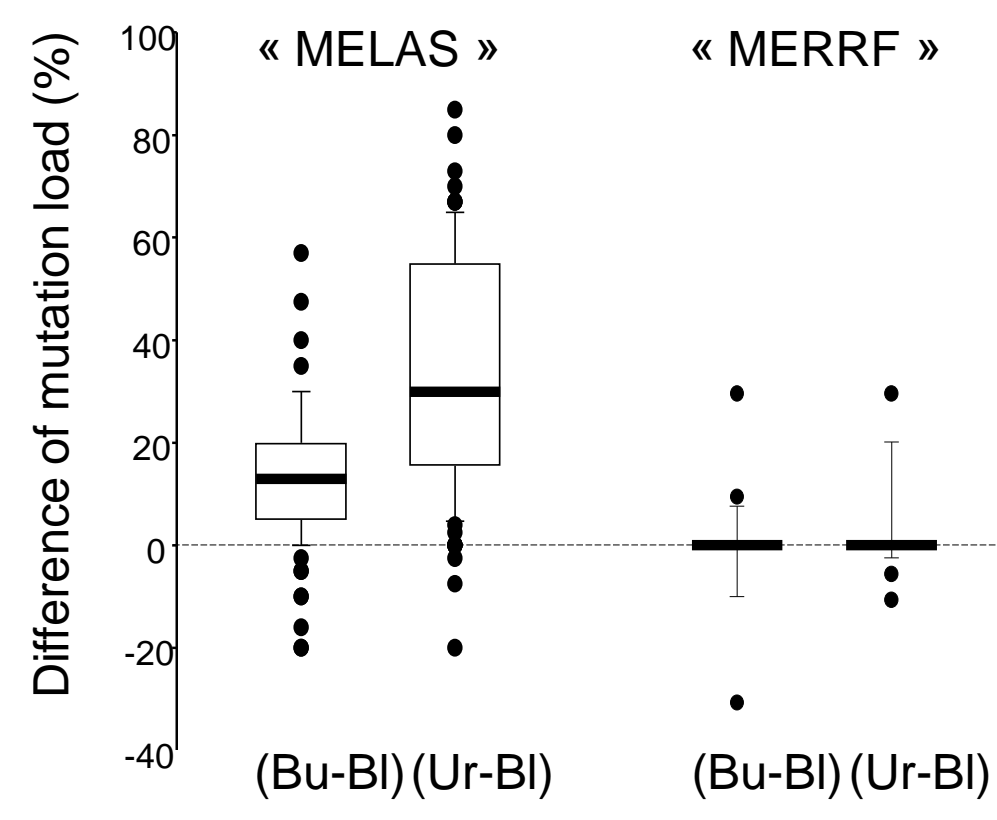

Figure 2 